\title{
CHARACTERIZATION OF THE AHP WITH ADJUSTMENTS OF WEIGHTS OF ALTERNATIVES AS AN OPTIMAL SOLUTION
}

\author{
Youichi Iida \\ Faculty of business administration and information \\ Tokyo University of Science, Suwa \\ Chino, Nagano, JAPAN \\ E-mail: iida@rs.suwa.tus.ac.jp
}

\begin{abstract}
The analytic hierarchy process (AHP) is decision-making method proposed by T.L.Saaty in the 1970s. In ISAHP2011, I proposed a different way from the traditional AHP in order to synthesize weights of alternatives with respect to criteria and called it the AHP with adjustments of weights of alternatives there. This method is based on a concept of weighted summation model (WSM), which is well-known as a simplest multi-criteria analysis method. WSM is essentially able to deal with evaluation values represented by absolute numbers. By the way, it is easily seen that a ratio of overall evaluation values of alternatives with WSM is calculated directly from a ratio of evaluation values of alternatives with respect to criteria. Alternatives are often not able to be evaluated in a common measure with a unit with respect to a criterion, and so it is useful to also evaluate alternatives with respect to such criteria. In order to solve this problem I modified the AHP to propose a way. It includes a procedure called adjustment of weights of alternatives. I showed that a kind of validity of this method in terms of basic algebra there. In this paper, there are two purposes. One is showing validity of the method in optimal problems. The other is showing another version of this method in the selection problem of a best skater in (Iida, 2011). This version is more realistic than the original version in a competition which one player acts at a time in order.
\end{abstract}

Keywords: Weighted summation, AHP, relative evaluation, optimal solution

\section{Introduction}

The analytic hierarchy process (AHP) is decision-making method proposed by T.L.Saaty in the 1970s. He wrote in (Saaty, 1980) as follows: Of considerable interest to us must be the issue of how closely the priority vector developed by our method matches the "real" priority vector. One way to ascertain this is to apply the method to situations which allow the determination of the actual numbers. In such cases we wish to check how accurate the priority vector is. So I proposed a new process in (Iida, 2011) which can restore actual numbers as overall evaluation values with slightly modification of AHP. The way to synthesize weights of alternatives with respect to criteria is different from that of the AHP and we called it the AHP with adjustments of weights of alternatives. This method is based on the concept of weighted summation model (WSM), which is well-known as a simplest multicriteria analysis method.

WSM is essentially able to deal with evaluation values represented with absolute numbers. Then we expect a common measure with a unit like the dollar or the point to evaluate alternatives with respect to criteria. By the way, it is easily seen that a ratio of overall evaluation values of alternatives with WSM is calculated directly from a ratio of evaluation values of alternatives with respect to criteria. Alternatives are often not able to be evaluated in a common measure with a unit with respect to a criterion, for example which is intangible, and so it's useful to also evaluate alternatives with respect to such criteria. The method proposed in (Iida, 2011) is to do so.

Thus I can say that the method is weighted summation method for intangible alternatives. We expect by this method not the actual value for each alternative, but ratio of weights of all alternatives as 
overall evaluation values. So for simplicity I call this method "weighted summation ratio method" (WSRM) in this paper, though I already called it "the AHP with adjustments of weights of alternatives" in (Iida, 2011). We note that this WSRM is based on the concept of the AHP.

In (Iida, 2011), I showed that a kind of validity of WSRM in terms of basic algebra. Furthermore, I showed a numerical example of a selection problem of a best skater. There we evaluated three skaters with respect to four criteria which are Jump, Spin, Balance and Speed. We can suppose that these criteria have a point as a common measure without a unit. In the example, I applied paired comparisons with the scale of the AHP to calculate relative evaluation values of skater's performances with respect to them, while in general we can use any positive numbers for paired comparisons.

There are two purposes in this paper. One is showing the validity of WSRM in optimal problems. There we use a view of the AHP, but this is unlike the traditional AHP and the ANP (the analytic network process), because we don't consider influence between three clusters in a hierarchy, which are a goal, criteria and alternatives, and don't also use feedback or network structure.

I recognize WSRM to be the extended version of WSM with the AHP now, but we may be able to use Supermatrix in the ANP instead of WSRM, in particular, for adjustment of weights of alternatives. This is a future research assignment. The other purpose is showing another version of this method in the selection problem of a best skater. This is more realistic than the original version in a competition which one player acts at a time in order, though it is difficult to use this in real problems. This problem is discussed in Section 6 with relation between WSRM and the AHP.

\section{Relationship between weighted summation and the method}

In this section we clarify the purpose of WSRM proposed in (Iida, 2011). We deal with the hierarchy with one goal, three criteria and four alternatives in Figure 1.

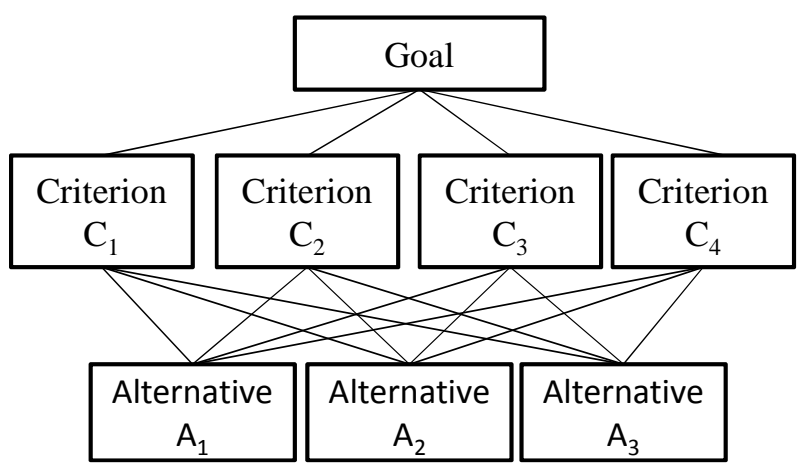

Figure 1. A hierarchy.

Next, we suppose that we have gotten Table 1 as priorities between criteria with respect to Goal.

Table 1. Priorities between criteria with respect to Goal in Figure 1.

\begin{tabular}{|l|l|l|l|l|}
\hline & $\mathrm{C}_{1}$ & $\mathrm{C}_{2}$ & $\mathrm{C}_{3}$ & $\mathrm{C}_{4}$ \\
\hline Priorities & $c_{1}$ & $c_{2}$ & $c_{3}$ & $c_{4}$ \\
\hline
\end{tabular}

In Table 1 we may set the condition $c_{1}+c_{2}+c_{3}+c_{4}=1$, while we don't need it in WSRM. Furthermore, we suppose that we have gotten Table 2 as the weights between alternatives with respect to criteria. Here we suppose that each $a_{i j}$ is an actual number which is evaluated with a unit like the dollar or the point.

Table 2. Weights by actual numbers between alternatives with respect to criteria in Figure 1 . 


\begin{tabular}{|l|l|l|l|l|}
\hline & $\mathrm{C}_{1}$ & $\mathrm{C}_{2}$ & $\mathrm{C}_{3}$ & $\mathrm{C}_{4}$ \\
\hline $\mathrm{A}_{1}$ & $a_{11}$ & $a_{12}$ & $a_{13}$ & $a_{14}$ \\
\hline $\mathrm{A}_{2}$ & $a_{21}$ & $a_{22}$ & $a_{23}$ & $a_{24}$ \\
\hline $\mathrm{A}_{3}$ & $a_{31}$ & $a_{32}$ & $a_{33}$ & $a_{34}$ \\
\hline
\end{tabular}

Then we calculate the overall evaluation values (OEV) of alternatives with WSM as follows:

$$
\left(\begin{array}{l}
\text { OEV of } A_{1} \\
\text { OEV of } A_{2} \\
\text { OEV of } A_{3}
\end{array}\right)=\left(\begin{array}{llll}
a_{11} & a_{12} & a_{13} & a_{14} \\
a_{21} & a_{22} & a_{23} & a_{24} \\
a_{31} & a_{32} & a_{33} & a_{34}
\end{array}\right)\left(\begin{array}{l}
c_{1} \\
c_{2} \\
c_{3} \\
c_{4}
\end{array}\right)=\left(\begin{array}{l}
c_{1} a_{11}+c_{2} a_{12}+c_{3} a_{13}+c_{4} a_{14} \\
c_{1} a_{21}+c_{2} a_{22}+c_{3} a_{23}+c_{4} a_{24} \\
c_{1} a_{31}+c_{2} a_{32}+c_{3} a_{33}+c_{4} a_{34}
\end{array}\right) .
$$

Thus we have OEV of $\mathrm{A}_{1}$ is $c_{1} a_{11}+c_{2} a_{12}+c_{3} a_{13}+c_{4} a_{14}$, OEV of $\mathrm{A}_{2}$ is $c_{1} a_{21}+c_{2} a_{22}+c_{3} a_{23}+c_{4} a_{24}$ and OEV of $\mathrm{A}_{3}$ is $c_{1} a_{31}+c_{2} a_{32}+c_{3} a_{33}+c_{4} a_{34}$. Now, we focus on the ratio of them and have the following for any positive number $A$ :

OEV of $\mathrm{A}_{1}: \mathrm{OEV}$ of $\mathrm{A}_{2}: \mathrm{OEV}$ of $\mathrm{A}_{3}$

$=\left(c_{1} a_{11}+c_{2} a_{12}+c_{3} a_{13}+c_{4} a_{14}\right):\left(c_{1} a_{21}+c_{2} a_{22}+c_{3} a_{23}+c_{4} a_{24}\right):\left(c_{1} a_{31}+c_{2} a_{32}+c_{3} a_{33}+c_{4} a_{34}\right)$

$=\left(c_{1} a_{11}+c_{2} a_{12}+c_{3} a_{13}+c_{4} a_{14}\right) / A:\left(c_{1} a_{21}+c_{2} a_{22}+c_{3} a_{23}+c_{4} a_{24}\right) / A:\left(c_{1} a_{31}+c_{2} a_{32}+c_{3} a_{33}+c_{4} a_{34}\right) / A$

$=\left\{c_{1}\left(a_{11} / A\right)+c_{2}\left(a_{12} / A\right)+c_{3}\left(a_{13} / A\right)+c_{4}\left(a_{14} / A\right)\right\}:\left\{c_{1}\left(a_{21} / A\right)+c_{2}\left(a_{22} / A\right)+c_{3}\left(a_{23} / A\right)+c_{4}\left(a_{24} / A\right)\right\}:\left\{c_{1}\left(a_{31} / A\right)+c_{2}\left(a_{32}\right.\right.$ $\left./ A)+c_{3}\left(a_{33} / A\right)+c_{4}\left(a_{34} / A\right)\right\}$.

We notice that if we put $A=c_{1}+c_{2}+c_{3}+c_{4}$ in the above equation, then it means setting the condition $c_{1}+c_{2}+c_{3}+c_{4}=1$ in Table 1 . The last continuous ratio means a ratio of OEV of alternatives with WSM. This isn't decided uniquely and so we define continuous ratio with the total of its elements being 1 as the final answer, which is called normalized overall evaluation ratio (NOER) of alternatives. Furthermore, we call each element of NOER normalized overall evaluation values (NOEV) of alternative. Our purpose is calculating NOER, consequently NOEV, directly from weights table of alternatives as Table 3.

Table 3. Weights ratios between alternatives with respect to criteria in Figure 1.

\begin{tabular}{|c|c|c|c|c|}
\hline & $\mathrm{C}_{1}$ & $\mathrm{C}_{2}$ & $\mathrm{C}_{3}$ & $\mathrm{C}_{4}$ \\
\hline $\mathrm{A}_{1}$ & $a_{11} / A$ & $a_{12} / A$ & $a_{13} / A$ & $a_{14} / A$ \\
\hline $\mathrm{A}_{2}$ & $a_{21} / A$ & $a_{22} / A$ & $a_{23} / A$ & $a_{24} / A$ \\
\hline $\mathrm{A}_{3}$ & $a_{31} / A$ & $a_{32} / A$ & $a_{33} / A$ & $a_{34} / A$ \\
\hline
\end{tabular}

In particular, when we set $A=a_{11}+a_{12}+a_{13}+a_{14}+a_{21}+a_{22}+a_{23}+a_{24}+a_{31}+a_{32}+a_{33}+a_{34}$, which is the total of element in Table 2, Table 3 is equivalent to a guessed table with the total of elements being 1 . We recall such Table 3 was defined as the representative of evaluation ratio tables in (Iida, 2011), which is by elementary algebra. Since this fact, we need to guess only a ratio of $a_{i j}$ in Table 2 (or Table 3 ) in order to calculate NOEV of alternatives with WSM, and the purpose of WSRM is guessing the representative of evaluation ratio tables.

Here, we introduce an example which the AHP don't work well. Before that, I confirm that calculating such ratio isn't a purpose of the AHP. In fact, we use different scale from the AHP in this example. Firstly, we consider Table 4 with elements being represented in the dollar.

Table 4. Weights in the dollar between alternatives with respect to criteria.

\begin{tabular}{|c|c|c|c|c|}
\hline & $\mathrm{C}_{1}$ & $\mathrm{C}_{2}$ & $\mathrm{C}_{3}$ & $\mathrm{C}_{4}$ \\
\hline $\mathrm{A}_{1}$ & $50 \$$ & $5 \$$ & $40 \$$ & $3 \$$ \\
\hline $\mathrm{A}_{2}$ & $60 \$$ & $6 \$$ & $30 \$$ & $4 \$$ \\
\hline $\mathrm{A}_{3}$ & $70 \$$ & $7 \$$ & $50 \$$ & $5 \$$ \\
\hline
\end{tabular}

Then we calculate Table 5 with the AHP, namely with normalization in each column of Table 4. 
Table 5. Weights guessed with the AHP according to Table 4.

\begin{tabular}{|c|c|c|c|c|}
\hline & $\mathrm{C}_{1}$ & $\mathrm{C}_{2}$ & $\mathrm{C}_{3}$ & $\mathrm{C}_{4}$ \\
\hline $\mathrm{A}_{1}$ & 0.278 & 0.278 & 0.333 & 0.250 \\
\hline $\mathrm{A}_{2}$ & 0.333 & 0.333 & 0.250 & 0.333 \\
\hline $\mathrm{A}_{3}$ & 0.389 & 0.389 & 0.417 & 0.417 \\
\hline
\end{tabular}

We compare Table 5 with Table 4 . Weights of three alternatives with respect to $\mathrm{C}_{1}$ and $\mathrm{C}_{2}$ in Table 5 are the same as each other, while those in Table 4 are different. Furthermore, the difference of weights of $A_{1}$ and $A_{2}$ with respect to $C_{3}$ in Table 4 is reducing in Table 5, while the difference of $A_{1}$ and $A_{2}$ with respect to $\mathrm{C}_{4}$ in Table 4 is almost the same as in Table 5. These fact influences OEV of alternatives in the AHP. For example, we set $c_{1}=c_{2}=0.125, c_{3}=0.25$ and $c_{4}=0.5$. Then we have Table 6 with weighted evaluation value of each alternative.

Table 6. NOEV guessed with the AHP according to Tables 4 and the weights of criteria.

\begin{tabular}{|c|c|c|c|c|c|}
\hline & $\mathrm{C}_{1}$ & $\mathrm{C}_{2}$ & $\mathrm{C}_{3}$ & $\mathrm{C}_{4}$ & NOEV \\
\hline $\mathrm{A}_{1}$ & $\begin{array}{c}0.278 \times 0.125 \\
=0.035\end{array}$ & $\begin{array}{c}0.278 \times 0.125 \\
=0.035\end{array}$ & $\begin{array}{c}0.333 \times 0.250 \\
=0.083\end{array}$ & $\begin{array}{c}0.250 \times 0.500 \\
=0.125\end{array}$ & 0.278 \\
\hline $\mathrm{A}_{2}$ & $\begin{array}{c}0.333 \times 0.125 \\
=0.042\end{array}$ & $\begin{array}{c}0.333 \times 0.125 \\
=0.042\end{array}$ & $\begin{array}{l}0.250 \times 0.250 \\
\quad=0.063\end{array}$ & $\begin{array}{c}0.333 \times 0.500 \\
=0.167\end{array}$ & 0.313 \\
\hline $\mathrm{A}_{3}$ & $\begin{array}{c}0.389 \times 0.125 \\
=0.049\end{array}$ & $\begin{array}{l}0.389 \times 0.125 \\
=0.049\end{array}$ & $\begin{array}{l}0.417 \times 0.250 \\
=0.104\end{array}$ & $\begin{array}{l}0.417 \times 0.500 \\
=0.208\end{array}$ & 0.410 \\
\hline & & & & Total & 1.000 \\
\hline
\end{tabular}

On the other hand, we have Table 7 with WSM.

Table 7. NOEV calculated with WSM according to Table 4 and the weights of criteria.

\begin{tabular}{|c|c|c|c|c|c|c|}
\hline & $\mathrm{C}_{1}$ & $\mathrm{C}_{2}$ & $\mathrm{C}_{3}$ & $\mathrm{C}_{4}$ & Total & NOEV \\
\hline $\mathrm{A}_{1}$ & $\begin{array}{c}50 \times 0.125 \\
=6.25\end{array}$ & $\begin{array}{c}5 \times 0.125 \\
=0.625\end{array}$ & $\begin{array}{c}40 \times 0.250 \\
=10\end{array}$ & $\begin{array}{c}3 \times 0.500 \\
=1.5\end{array}$ & 18.375 & 0.302 \\
\hline $\mathrm{A}_{2}$ & $\begin{array}{c}60 \times 0.125 \\
=7.5\end{array}$ & $\begin{array}{c}6 \times 0.125 \\
=0.75\end{array}$ & $\begin{array}{c}30 \times 0.250 \\
=7.5\end{array}$ & $\begin{array}{c}4 \times 0.500 \\
=2\end{array}$ & 17.75 & 0.292 \\
\hline $\mathrm{A}_{3}$ & $\begin{array}{c}70 \times 0.125 \\
=8.75\end{array}$ & $\begin{array}{c}7 \times 0.125 \\
=0.875\end{array}$ & $\begin{array}{c}50 \times 0.250 \\
=12.5\end{array}$ & $\begin{array}{c}5 \times 0.500 \\
=2.5\end{array}$ & 24.625 & 0.405 \\
& & Total & 60.75 & 1.000 \\
\hline
\end{tabular}

We note again that NOEV in Table 7 is not for the purpose of the AHP. If we would use the AHP, for example, then we might divide Table 4 (or the hierarchy in Figure 1) into two: one is what consists of $\mathrm{C}_{1}$ and $\mathrm{C}_{3}$ and the other is what consists of $\mathrm{C}_{2}$ and $\mathrm{C}_{4}$ : Moreover, we may evaluate weights of alternatives as $A_{1}: A_{2}: A_{3}=7: 8: 9$ with respect to $C_{1}$ with the scale of the AHP, $A_{1}: A_{2}: A_{3}=1: 2: 3$ with respect to $C_{2}$ and so on. Anyway, it's important that the AHP can't restore Table 2 (or Table 4) which plays the important role in WSM (or WSRM), respectively. On the other hand, we obtain Table 8 with the WSRM, namely with adjustment of weights of alternatives.

Table 8. Normalized weights guessed with WSRM according to Table 4.

\begin{tabular}{|c|c|c|c|c|}
\hline & $\mathrm{C}_{1}$ & $\mathrm{C}_{2}$ & $\mathrm{C}_{3}$ & $\mathrm{C}_{4}$ \\
\hline $\mathrm{A}_{1}$ & 0.152 & 0.015 & 0.121 & 0.009 \\
\hline $\mathrm{A}_{2}$ & 0.182 & 0.018 & 0.091 & 0.012 \\
\hline $\mathrm{A}_{3}$ & 0.212 & 0.021 & 0.152 & 0.015 \\
\hline
\end{tabular}

From Table 8 we have Table 9 and NOEV of alternatives at the end, which is the same as in Table 7.

Table 9. NOEV guessed with WSRM according to Table 8 and the weights of criteria. 


\begin{tabular}{|c|c|c|c|c|c|c|}
\hline & $\mathrm{C}_{1}$ & $\mathrm{C}_{2}$ & $\mathrm{C}_{3}$ & $\mathrm{C}_{4}$ & Total & NOEV \\
\hline $\mathrm{A}_{1}$ & $\begin{array}{c}0.152 \times 0.125 \\
=0.019\end{array}$ & $\begin{array}{c}0.015 \times 0.125 \\
=0.002\end{array}$ & $\begin{array}{l}0.121 \times 0.250 \\
\quad=0.030\end{array}$ & $\begin{array}{c}0.009 \times 0.500 \\
=0.005\end{array}$ & 0.056 & 0.302 \\
\hline $\mathrm{A}_{2}$ & $\begin{array}{c}0.182 \times 0.125 \\
=0.023\end{array}$ & $\begin{array}{c}0.018 \times 0.125 \\
=0.002\end{array}$ & $\begin{array}{l}0.091 \times 0.250 \\
=0.023\end{array}$ & $\begin{array}{l}0.012 \times 0.500 \\
=0.006\end{array}$ & 0.054 & 0.292 \\
\hline $\mathrm{A}_{3}$ & $\begin{array}{c}0.212 \times 0.125 \\
=0.027\end{array}$ & $\begin{array}{c}0.021 \times 0.125 \\
=0.003\end{array}$ & $\begin{array}{c}0.152 \times 0.250 \\
=0.038\end{array}$ & $\begin{array}{c}0.015 \times 0.500 \\
=0.008\end{array}$ & 0.075 & 0.405 \\
\hline & & & & Total & 0.184 & 1.000 \\
\hline
\end{tabular}

\section{Calculation method in the method}

In this section we introduce the method proposed in (Iida, 2011), which is called WSRM in this paper. We start from the three-level hierarchy in Figure1, which has one goal (Goal), four criteria $\left(C_{1}, C_{2}, C_{3}\right.$ and $\left.\mathrm{C}_{4}\right)$ and three alternatives $\left(\mathrm{A}_{1}, \mathrm{~A}_{2}\right.$ and $\left.\mathrm{A}_{3}\right)$. And we calculate Table 1, which consists of priorities between criteria with respect to Goal.

Next, we guess two tables, Tables 10 and 11, which consist of weights of alternatives with respect to criteria and weights of each alternative with respect to all criteria, respectively. Here we note that the latter isn't mutual evaluation, but guessing ratio of weights of alternative with respect to criteria in Table 3 (or Table 2), for example, $a_{11} / A: a_{12} / A: a_{13} / A: a_{14} / A, \quad a_{21} / A: a_{22} / A: a_{23} / A: a_{24} / A$ and $a_{31} / A: a_{32} / A: a_{33} / A: a_{34} / A$.

Table 10. Weights of all alternatives with respect to each criterion.

\begin{tabular}{|l|l|l|l|l|}
\hline & $\mathrm{C}_{1}$ & $\mathrm{C}_{2}$ & $\mathrm{C}_{3}$ & $\mathrm{C}_{4}$ \\
\hline $\mathrm{A}_{1}$ & $v_{11}$ & $v_{12}$ & $v_{13}$ & $v_{14}$ \\
\hline $\mathrm{A}_{2}$ & $v_{21}$ & $v_{22}$ & $v_{23}$ & $v_{24}$ \\
\hline $\mathrm{A}_{3}$ & $v_{31}$ & $v_{32}$ & $v_{33}$ & $v_{34}$ \\
\hline
\end{tabular}

Table 11. Weights of each alternative with respect to all criteria.

\begin{tabular}{|l|l|l|l|}
\hline & $\mathrm{A}_{1}$ & $\mathrm{~A}_{2}$ & $\mathrm{~A}_{3}$ \\
\hline $\mathrm{C}_{1}$ & $w_{11}$ & $w_{21}$ & $w_{31}$ \\
\hline $\mathrm{C}_{2}$ & $w_{12}$ & $w_{22}$ & $w_{32}$ \\
\hline $\mathrm{C}_{3}$ & $w_{13}$ & $w_{23}$ & $w_{33}$ \\
\hline $\mathrm{C}_{4}$ & $w_{14}$ & $w_{24}$ & $w_{34}$ \\
\hline
\end{tabular}

In the next step, we need to combine these two tables to guess Table 3 with a certain way. We might be able to use Supermatrix of the ANP, but I proposed in (Iida, 2011) a way with a procedure of adjustment of weights of alternatives because our purpose is guessing Table 3 or an equivalent table to Table 3. See (Iida, 2011) for detail. Consequently, we have Table 12. I didn't notice this table there, but showed this table in (Iida, 2012b).

Table 12. Guessed evaluation ratio tables of alternatives with respect to criteria (criteria-oriented WSRM).

\begin{tabular}{|c|c|c|c|c|}
\hline & $\mathrm{C}_{1}$ & $\mathrm{C}_{2}$ & $\mathrm{C}_{3}$ & $\mathrm{C}_{4}$ \\
\hline $\mathrm{A}_{1}$ & $v_{11} \times \sqrt[3]{\prod_{i=1}^{3} \frac{w_{i 1}}{v_{i 1}}}$ & $v_{12} \times \sqrt[3]{\prod_{i=1}^{3} \frac{w_{i 2}}{v_{i 2}}}$ & $v_{13} \times \sqrt[3]{\prod_{i=1}^{3} \frac{w_{i 3}}{v_{i 3}}}$ & $v_{14} \times \sqrt[3]{\prod_{i=1}^{3} \frac{w_{i 4}}{v_{i 4}}}$ \\
\hline $\mathrm{A}_{2}$ & $v_{21} \times \sqrt[3]{\prod_{i=1}^{3} \frac{w_{i 1}}{v_{i 1}}}$ & $v_{22} \times \sqrt[3]{\prod_{i=1}^{3} \frac{w_{i 2}}{v_{i 2}}}$ & $v_{23} \times \sqrt[3]{\prod_{i=1}^{3} \frac{w_{i 3}}{v_{i 3}}}$ & $v_{24} \times \sqrt[3]{\prod_{i=1}^{3} \frac{w_{i 4}}{v_{i 4}}}$ \\
\hline
\end{tabular}




$$
\begin{array}{|l|l|l|l|l}
\mathrm{A}_{3} & v_{31} \times \sqrt[3]{\prod_{i=1}^{3} \frac{w_{i 1}}{v_{i 1}}} & v_{32} \times \sqrt[3]{\prod_{i=1}^{3} \frac{w_{i 2}}{v_{i 2}}} & v_{33} \times \sqrt[3]{\prod_{i=1}^{3} \frac{w_{i 3}}{v_{i 3}}} v_{34} \times \sqrt[3]{\prod_{i=1}^{3} \frac{w_{i 4}}{v_{i 4}}} \\
\hline
\end{array}
$$

For example, from Table 4 we have Tables 13 and 14 corresponding to Tables 10 and 11, respectively. Here we used normalization in the AHP/ANP for the column and the row in Table 4, respectively, though we don't need such normalization in WSRM.

Table 13. Weights of alternatives with respect to each criterion according to Table 4.

\begin{tabular}{|c|c|c|c|c|}
\hline & $\mathrm{C}_{1}$ & $\mathrm{C}_{2}$ & $\mathrm{C}_{3}$ & $\mathrm{C}_{4}$ \\
\hline $\mathrm{A}_{1}$ & 0.278 & 0.278 & 0.333 & 0.250 \\
\hline $\mathrm{A}_{2}$ & 0.333 & 0.333 & 0.250 & 0.333 \\
\hline $\mathrm{A}_{3}$ & 0.389 & 0.389 & 0.417 & 0.417 \\
\hline
\end{tabular}

Table 14. Weights among criteria in each alternative according to Table 4.

\begin{tabular}{|l|c|c|c|}
\hline & $\mathrm{A}_{1}$ & $\mathrm{~A}_{2}$ & $\mathrm{~A}_{3}$ \\
\hline $\mathrm{C}_{1}$ & 0.510 & 0.600 & 0.530 \\
\hline $\mathrm{C}_{2}$ & 0.051 & 0.060 & 0.053 \\
\hline $\mathrm{C}_{3}$ & 0.408 & 0.300 & 0.379 \\
\hline $\mathrm{C}_{4}$ & 0.031 & 0.040 & 0.038 \\
\hline
\end{tabular}

We remark that Table 13 is necessarily the same as Table 5. Here from Tables 13 and 14 we have Table 15 according to Table 12 .

Table 15. Weights obtained by combining Tables 13 and 14 according to Table 12.

\begin{tabular}{|c|c|c|c|c|}
\hline & $\mathrm{C}_{1}$ & $\mathrm{C}_{2}$ & $\mathrm{C}_{3}$ & $\mathrm{C}_{4}$ \\
\hline $\mathrm{A}_{1}$ & 0.459 & 0.046 & 0.367 & 0.028 \\
\hline $\mathrm{A}_{2}$ & 0.551 & 0.055 & 0.275 & 0.037 \\
\hline $\mathrm{A}_{3}$ & 0.642 & 0.064 & 0.459 & 0.046 \\
\hline
\end{tabular}

We obtain Table 8 with dividing each element in Table 15 by the total of its elements. Consequently, we have the same NOEV of alternatives as in Table 9 (Table 7).

\section{Characterization of the method in optimization problems}

In this section, we characterize Table 12 as an optimal solution, which is a purpose of this paper. We recall that the essential purpose of WSRM is guessing Table 2 with $\sum_{i=1}^{3} \sum_{j=1}^{4} a_{i j}=1$. We have the following (cf. (Iida, 2012b)):

Theorem 1. Table 16 satisfies that $s_{1 j}: s_{2 j}: s_{3 j}=a_{1 j}: a_{2 j}: a_{3 j}\left(j=1,2,3\right.$ and 4) and $s_{i 1}: s_{i 2}: s_{i 3}: s_{i 4}=a_{i 1}: a_{i 2}$ : $a_{i 3}: a_{i 4}(i=1,2$ and 3$)$, where $a_{i j}$ is in Table 2 if only if there exists a real number $k$ such that $s_{i j}=k a_{i j}$ $(i=1,2$ and $3 ; j=1,2,3$ and 4$)$.

Table 16. Evaluation ratio table of alternatives with respect to criteria corresponding to Table 2.

\begin{tabular}{|l|l|l|l|l|}
\hline & $\mathrm{C}_{1}$ & $\mathrm{C}_{2}$ & $\mathrm{C}_{3}$ & $\mathrm{C}_{4}$ \\
\hline $\mathrm{A}_{1}$ & $s_{11}$ & $s_{12}$ & $s_{13}$ & $s_{14}$ \\
\hline $\mathrm{A}_{2}$ & $s_{21}$ & $s_{22}$ & $s_{23}$ & $s_{24}$ \\
\hline $\mathrm{A}_{3}$ & $s_{31}$ & $s_{32}$ & $s_{33}$ & $s_{34}$ \\
\hline
\end{tabular}

Proof. It is sufficient only to show the necessary condition. It follows from the assumption that there exist real numbers $p_{j}$ and $q_{i}$ such that $s_{1 j}=p_{j} a_{1 j}, s_{2 j}=p_{j} a_{2 j}, s_{3 j}=p_{j} a_{3 j}\left(j=1,2,3\right.$ and 4) and $s_{i 1}=q_{i} a_{i 1}, s_{i 2}=q_{i}$ $a_{i 2}, s_{i 3}=q_{i} a_{i 3 \text { and }} s_{i 4}=q_{i} a_{i 4}$ (i=1,2 and 3). So we have $s_{i j}=p_{j} a_{i j}=q_{i} a_{i j}$ and $p_{j}=q_{i}$ for any numbers $i$ and $j$. The theorem is proved.

(Q.E.D.) 
From this theorem we know that if there exists a real number $k$ such that $v_{i j}=k w_{i j}(i=1,2$ and $3 ; j=1$, 2,3 and 4), then we may put $a_{i j}=v_{i j}(i=1,2$ and $3 ; j=1,2,3$ and 4$)$ in Table 2. In particular, in this case we can also restore it by AHP.

Now we consider real numbers $A_{1}, A_{2}, A_{3}$ and $A_{4}$ such that

$$
\begin{aligned}
& v_{11} A_{1}: v_{12} A_{2}: v_{13} A_{3}: v_{14} A_{4}=w_{11}: w_{12}: w_{13}: w_{14}, \\
& v_{21} A_{1}: v_{22} A_{2}: v_{23} A_{3}: v_{24} A_{4}=w_{21}: w_{22}: w_{23}: w_{24}, \\
& v_{31} A_{1}: v_{32} A_{2}: v_{33} A_{3}: v_{34} A_{4}=w_{31}: w_{32}: w_{33}: w_{34} .
\end{aligned}
$$

Here we remark that $v_{1 j} A_{j}: v_{2 j} A_{j}: v_{3 j} A_{j}=v_{1 j}: v_{2 j}: v_{3 j}(j=1,2,3$ and 4$)$ in the above equations, i.e., the relationship between elements in each column of Table 2 is preserved. However, generally, such numbers don't exist. On the other hand, we have the following:

$$
\begin{aligned}
& v_{11}\left(\frac{w_{11}}{v_{11}}\right): v_{12}\left(\frac{w_{12}}{v_{12}}\right): v_{13}\left(\frac{w_{13}}{v_{13}}\right): v_{14}\left(\frac{w_{14}}{v_{14}}\right)=w_{11}: w_{12}: w_{13}: w_{14}, \\
& v_{21}\left(\frac{w_{21}}{v_{21}}\right): v_{22}\left(\frac{w_{22}}{v_{22}}\right): v_{23}\left(\frac{w_{23}}{v_{23}}\right): v_{24}\left(\frac{w_{24}}{v_{24}}\right)=w_{21}: w_{22}: w_{23}: w_{24}, \\
& v_{31}\left(\frac{w_{31}}{v_{31}}\right): v_{32}\left(\frac{w_{32}}{v_{32}}\right): v_{33}\left(\frac{w_{33}}{v_{33}}\right): v_{34}\left(\frac{w_{34}}{v_{34}}\right)=w_{31}: w_{32}: w_{33}: w_{34} .
\end{aligned}
$$

So we make the following optimization problem, which is solved with logarithmic least squares method:

Problem. Find positive numbers $A_{1}, A_{2}, A_{3}$ and $A_{4}$ for given positive numbers $w_{i j}$ ( $i=1,2$ and $3 ; j=1,2$, 3 and 4) with the minimum value of $\sum_{i=1}^{3} \sum_{j=1}^{4}\left(\log \left(e_{i j}\right)\right)^{2}$ subject that $A_{1} e_{i 1}=\frac{w_{i 1}}{v_{i 1}}(i=1,2,3)$, $A_{2} e_{i 2}=\frac{w_{i 2}}{v_{i 2}}(i=1,2,3), A_{3} e_{i 3}=\frac{w_{i 3}}{v_{i 3}}(i=1,2,3)$, and $A_{4} e_{i 4}=\frac{w_{i 4}}{v_{i 4}}(i=1,2,3)$.

Then the solution is that $A_{1}=\sqrt[3]{\prod_{i=1}^{3} \frac{w_{i 1}}{v_{i 1}}}, A_{2}=\sqrt[3]{\prod_{i=1}^{3} \frac{w_{i 2}}{v_{i 2}}}, A_{3}=\sqrt[3]{\prod_{i=1}^{3} \frac{w_{i 3}}{v_{i 3}}}$ and $A_{4}=\sqrt[3]{\prod_{i=1}^{3} \frac{w_{i 4}}{v_{i 4}}}$.

Proof. It is sufficient to deal with equation $A_{1} e_{i 1}=\frac{w_{i 1}}{v_{i 1}}(i=1,2,3)$. These are equivalent to $\log \left(e_{i 1}\right)=\log \left(\frac{w_{i 1}}{v_{i 1}}\right)-\log \left(A_{1}\right)(i=1,2,3)$. We set $f\left(A_{1}\right)=\sum_{i=1}^{3}\left(\log \left(e_{i 1}\right)\right)^{2}=\sum_{i=1}^{3}\left(\log \left(\frac{w_{i 1}}{v_{i 1}}\right)-\right.$ $\left.\log \left(A_{1}\right)\right)^{2}$. Then we have $f^{\prime}\left(A_{1}\right)=\sum_{i=1}^{3} 2\left(\log \left(\frac{w_{i 1}}{v_{i 1}}\right)-\log \left(A_{1}\right)\right)\left(-\frac{1}{A_{1}}\right)$. When $f^{\prime}\left(A_{1}\right)=0$, we have $f^{\prime}\left(A_{1}\right)=\sum_{i=1}^{3}\left(\log \left(\frac{w_{i 1}}{v_{i 1}}\right)-\log \left(A_{1}\right)\right)=0$, which is equivalent to $\log \left(\prod_{i=1}^{3} \frac{w_{i 1}}{v_{i 1}}\right)-\log \left(A_{1}\right)^{3}$ $=0$ and $A_{1}=\sqrt[3]{\prod_{i=1}^{3} \frac{w_{i 1}}{v_{i 1}}}$. It is shown.

From this we obtain Table 12. Indeed, $(i, j)$-element in Table 12 is $v_{i j} A_{j}=v_{i j} \times \sqrt[3]{\prod_{i=1}^{3} \frac{w_{i j}}{v_{i j}}}$. In this way to combine two tables we chose preservation of not relations between columns of Table 11 corresponding to rows of Table 2, but relations between columns of Table 10 corresponding to column of Table 2 . This is because it's generally easier and more stable to compare alternatives pairly with respect to each criterion like the AHP than each alternative with all criteria pairly.

\section{Another version of example of selecting the bet skater}

We showed a selection problem of a best skater in (Iida, 2011) in order to explain WSRM in the general case. The method is essentially equivalent to calculating Table 12. By the way, this is a 
competition which one player acts at a time in order. In such a case we will calculate Table 11 before Table 10. In fact, after the first player $\mathrm{A}_{1}$ acted, we calculate $w_{11}: w_{12}: w_{13}: w_{14}$ with respect to each criterion. Next, after the second player $\mathrm{A}_{2}$ did, we calculate $w_{21}: w_{22}: w_{23}: w_{24}$ with respect to each criterion. Finally, after the final player $\mathrm{A}_{3}$ did, we calculate $w_{31}: w_{32}: w_{33}: w_{34}$ with respect to each criterion and consequently, we obtain Table 11. After this, we compare performance of players pairly with respect to each criterion and obtain Table 10. This means that it's easier and more exact to compare his/her performance with respect to criteria pairly than them with each criteria pairly, though I wrote "it's generally easier and more stable to compare alternatives pairly with respect to each criterion like the AHP than each alternative with all criteria pairly" at the end of Section 4. Thus we propose Table 17 in these cases instead of Table 12. We call WSRM with Table 12 criteria-oriented WSRM and WSRM with Table 17 alternatives-oriented WSRM.

Table 17. Guessed evaluation ratio tables of alternatives with respect to criteria (alternatives-oriented WSRM).

\begin{tabular}{|c|c|c|c|c|}
\hline $\mathrm{A}_{1}$ & $w_{11} \times \sqrt[4]{\prod_{j=1}^{4} \frac{v_{1 j}}{w_{1 j}}}$ & $w_{12} \times \sqrt[4]{\prod_{j=1}^{4} \frac{v_{1 j}}{w_{1 j}}}$ & $w_{13} \times \sqrt[4]{\prod_{j=1}^{4} \frac{v_{1 j}}{w_{1 j}}}$ & $w_{14} \times \sqrt[4]{\prod_{j=1}^{4} \frac{v_{1 j}}{w_{1 j}}}$ \\
\hline $\mathrm{A}_{2}$ & $w_{21} \times \sqrt[4]{\prod_{j=1}^{4} \frac{v_{2 j}}{w_{2 j}}}$ & $w_{22} \times \sqrt[4]{\prod_{j=1}^{4} \frac{v_{2 j}}{w_{2 j}}}$ & $w_{23} \times \sqrt[4]{\prod_{i=1}^{4} \frac{v_{2 j}}{w_{2 j}}}$ & $w_{24} \times \sqrt[4]{\prod_{j=1}^{4} \frac{v_{2 j}}{w_{2 j}}}$ \\
\hline $\mathrm{A}_{3}$ & $w_{31} \times \sqrt[4]{\prod_{j=1}^{4} \frac{v_{3 j}}{w_{3 j}}}$ & $w_{32} \times \sqrt[4]{\prod_{j=1}^{4} \frac{v_{3 j}}{w_{3 j}}}$ & $w_{33} \times \sqrt[4]{\prod_{j=1}^{4} \frac{v_{3 j}}{w_{3 j}}}$ & $w_{34} \times \sqrt[4]{\prod_{j=1}^{4} \frac{v_{3 j}}{w_{3 j}}}$ \\
\hline
\end{tabular}

Now, we compare NOEVs by Tables 12 and 17. We recall that we had in (Iida, 2011) Figure 2 as the hierarchy and Table 18 as evaluation ratio between criteria with respect to Goal. Furthermore, we had Tables 19 and 20 corresponding to Tables 11 and 10, respectively.

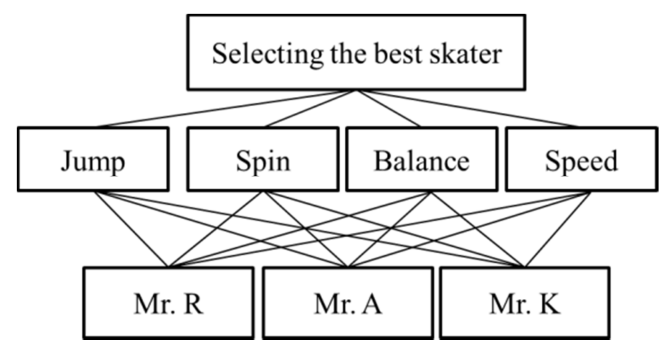

Figure 2. A competition of ice skating.

Table 18. Weights of criteria with respect to Goal.

\begin{tabular}{|c|c|c|c|c||c|}
\hline & Jump & Spin & Balance & Speed & Total \\
\hline Weights & 0.657 & 0.203 & 0.094 & 0.046 & 1.000 \\
\hline \multicolumn{5}{|c}{ Note. Total doesn't always need to be 1.}
\end{tabular}

Furthermore, we have Table 19 and 20 by paired comparison. Tables 19 and 20 are corresponding to Tables 10 and 11, respectively.

Table 19. Weights of each alternative with respect to criteria.

\begin{tabular}{|l|c|c|c|}
\hline & Mr. R & Mr. A & Mr. K \\
\hline Jump & 0.565 & 0.111 & 0.596 \\
\hline Spin & 0.262 & 0.732 & 0.266 \\
\hline Balance & 0.118 & 0.049 & 0.042 \\
\hline Speed & 0.055 & 0.108 & 0.097 \\
\hline
\end{tabular}

Table 20. Weights of alternatives with respect to each criterion. 


\begin{tabular}{|l|c|c|c|c|}
\hline & Jump & Spin & Balance & Speed \\
\hline Mr. R & 0.259 & 0.103 & 0.540 & 0.109 \\
\hline Mr. A & 0.105 & 0.682 & 0.163 & 0.309 \\
\hline Mr. K & 0.637 & 0.216 & 0.297 & 0.582 \\
\hline
\end{tabular}

We combine Tables 19 and 20 according to Table 17 to obtain Table 21. Consequently, we obtain Table 22 with Tables 21 and 18.

Table 21. Weights of alternatives with respect to each criterion.

\begin{tabular}{|l|c|c|c|c|}
\hline & Jump & Spin & Balance & Speed \\
\hline Mr. R & 0.639 & 0.296 & 0.133 & 0.062 \\
\hline Mr. A & 0.189 & 1.246 & 0.083 & 0.184 \\
\hline Mr. K & 1.468 & 0.655 & 0.103 & 0.239 \\
\hline
\end{tabular}

Table 22. NOEV guessed with alternatives-oriented WRSM for three players.

\begin{tabular}{|c|c|c|c|c|c|c|}
\hline & Jump & Spin & Balance & Speed & Total & NOEV \\
\hline $\begin{array}{l}\text { Mr. } \\
\text { R }\end{array}$ & $\begin{array}{c}0.639 \times 0.657 \\
=0.420\end{array}$ & $\begin{array}{c}0.296 \times 0.203 \\
=0.060\end{array}$ & $\begin{array}{c}0.133 \times 0.094 \\
=0.013\end{array}$ & $\begin{array}{c}0.062 \times 0.046 \\
=0.003\end{array}$ & 0.495 & 0.247 \\
\hline $\begin{array}{l}\text { Mr. } \\
\text { A }\end{array}$ & $\begin{array}{c}0.189 \times 0.657 \\
=0.124\end{array}$ & $\begin{array}{c}1.246 \times 0.203 \\
=0.253\end{array}$ & $\begin{array}{c}0.083 \times 0.094 \\
=0.008\end{array}$ & $\begin{array}{c}0.184 \times 0.046 \\
=0.008\end{array}$ & 0.393 & 0.196 \\
\hline $\begin{array}{l}\text { Mr. } \\
\mathrm{K}\end{array}$ & $\begin{array}{c}1.468 \times 0.657 \\
=0.965\end{array}$ & $\begin{array}{c}0.655 \times 0.203 \\
=0.133\end{array}$ & $\begin{array}{l}0.103 \times 0.094 \\
=0.010\end{array}$ & $\begin{array}{c}0.239 \times 0.046 \\
=0.011\end{array}$ & 1.118 & 0.557 \\
\hline & & & & Total & 2.007 & 1.000 \\
\hline
\end{tabular}

After all, we have Mr. A (0.196) < Mr. R (0.247) < Mr. K (0.557) from NOEV in Table 22. By the way, we remark that Mr. R (0.222) < Mr. A (0.256) < Mr. K (0.522) in (Iida, 2011), which is by criteria-oriented WSRM. We know that these rankings are different from each other. We need to discuss this problem more.

\section{Discussion}

I discuss the following three problems in this section: A way to guess Tables 10 and 11 and check consistency of them, a problem of getting different rankings with alternatives with criteria-oriented WRSM and alternatives-oriented WSRM as in Section 5 and a method other than WSRM in order to calculate the normalized overall evaluation values of alternatives with WSM.

Firstly, we will use paired comparisons to guess Tables 10 and 11 . This is natural because we need only ratio of weights. However, it is difficult to obtain both of Tables 10 and 11 with consistency. If we focus on only Table 10 (or Table 11), then we can use a check test shown in (Iida, 2011), which compares rankings of alternatives obtained by combining adjusted weights of alternatives for each alternative with priorities of criteria. About this problem we need to research when we can restore Table 2 according to Tables 10 and 11 (see the next paragraph).

Secondly, it may often happen that ranking of alternatives with criteria-oriented WRSM is different from that with alternatives-oriented WSRM as in Section 5. I think that it's very difficult to guess valid Tables 10 and 11 with paired comparisons at the same time. So if you guess Table 10 (or Table 11) previously, then we use criteria-oriented WRSM (or alternatives-oriented WRSM) with consistency check for Table 10 (or Table 11), respectively. Supermatrix in the ANP might be useful for this problem, while we need to change the purpose of guessing Tables 11, which is calculating mutual influences between clusters.

Finally, WSRM may not be practical although it is theoretically appropriate. So I need a more practical method to calculate the normalized overall evaluation ratio of alternatives with WSM. For example, we can consider a method with two kinds of adjustments. One is adjustment of scale to 
compare alternatives with respect to each criterion. By this all criteria will have the same measure to do so. We recall the selection problem of a best skater. Certainly, if we have a unit of weight, then we don't need WSRM. The other is adjustment of weights of alternatives with only one criterion. For example, we can adjust weights of alternatives in the first row of Tables 4 or 8 . This concept is surely one of linking pin, for example, in (Schoner, Wedley and Choo, 1993), (Wedley, 2009) and so on. It's important to be practical when considering a methodology of decision-making like the AHP. Now, we consider relationship between WSRM and the AHP. It is easily known that the AHP works well for the purpose of WSRM when we don't need both of two kinds of adjustment in the above argument. In fact, this happens in many cases.

\section{Conclusions}

In this paper we characterized the method proposed in (Iida, 2011), which was denoted by WSRM, as an optimal solution. I introduced two kinds of WSRM, which are criteria-oriented and alternativesoriented, according to how to combine two evaluation ratio tables of alternatives, for example, Tables 10 and 11. In Section 5 we explained the latter.

Finally, in Section 6 we discussed some problems of WSRM. I pointed out that this method is theoretically appropriate, although may not be practical. It's important to confirm that a method is theoretically appropriate, before improving a certain method to be more practical. Furthermore, we considered a relation between the AHP and WRSM at the end of Section 6. When we don't need two kinds of adjustment, the AHP works well for the purpose of WRSM.

It is future subjects to make this method easy-to-use and to examine whether the problem of WSRM is solvable by ANP from the viewpoint of WSRM. The AHP is the intelligible decision-making method intuitively. In order to make this merit more, I think that the argument of this paper is meaningful.

\section{REFERENCES}

Iida, Y. (2011). Analytic Hierarchy Process with Adjustments of Weights of Alternatives, Proceeding of the International Symposium on the Analytic Hierarchy Process, http://204.202.238.22/isahp2011/, 20-25.

Iida, Y. (2012a). A New Way to Make Decisions with Paired Comparisons. Intelligent Decision Technologies-Proceedings of the 4th International Conference on Intelligent Decision Technologies (IDT' 2012), Vol. 1, Springer-Verlag, 55-66.

Iida, Y. (2012b). Issues of Validity of a Method like Weighted Summation and the Analytic Hierarchy Process. Journal of Japanese Symposium on the Analytic Hierarchy Process, No.3, 63-70.

Saaty, T.L. (1980). The Analytic Hierarchy Process. New York: McGraw-Hill.

Saaty, T.L. (1994). Fundamentals of decision making and priority theory with the Analytic Hierarchy Process. Pittsburgh, PA: RWS Publications.

Schoner, B., Wedley, W.C. and Choo, E.U. (1993). A Unified Approach to AHP with Linking Pins. European Journal of Operations Research, Vol.64, 384-392.

Wedley, W.C. (2009). Issues in AHP/ANP: Linking and aggregating relative ratio scales. Proceedings of JSAHP2009, 17-37. 